\title{
An olivine fabric database: an interpretative frame for upper mantle seismology
}

\author{
W. Ben Ismail and D. Mainprice
}

CNRS, Laboratoire de Tectonophysique, Université de Montpellier II, Place E. Bataillon, 34095 CEDEX 05, France, email:walid@dstu.univ-montp2.fr

Recent investigations of teleseismic shear-wave splitting have shown that relationships between lattice preferred orientation (L.P.O.) and anisotropic seismic properties allow the determination of plastic flow directions (Mainprice and Nicolas, 1989; Mainprice and Silver, 1993), opening the way for studying the upper mantle tectonics (Silver, 1996; Barruol et al., 1996; Vauchez et al., 1997).

We present here a petrophysical database of upper mantle rocks on the basis of 110 olivine measured LPOs (Ben Ismail and Mainprice, 1998). The seismic properties of each aggregate were calculated combining LPO and single crystal elastic constant (See examples in Barruol and Mainprice, 1993) by the self-consistent method of Mainprice and Humbert (1994). The samples come from a variety of the upper mantle geodynamic envirnoments such as ophiolites, subduction zones, and Kimberlite pipes and display a wide range of micro-structures. We discuss the seismic properties of these rocks as a function of these parameters.

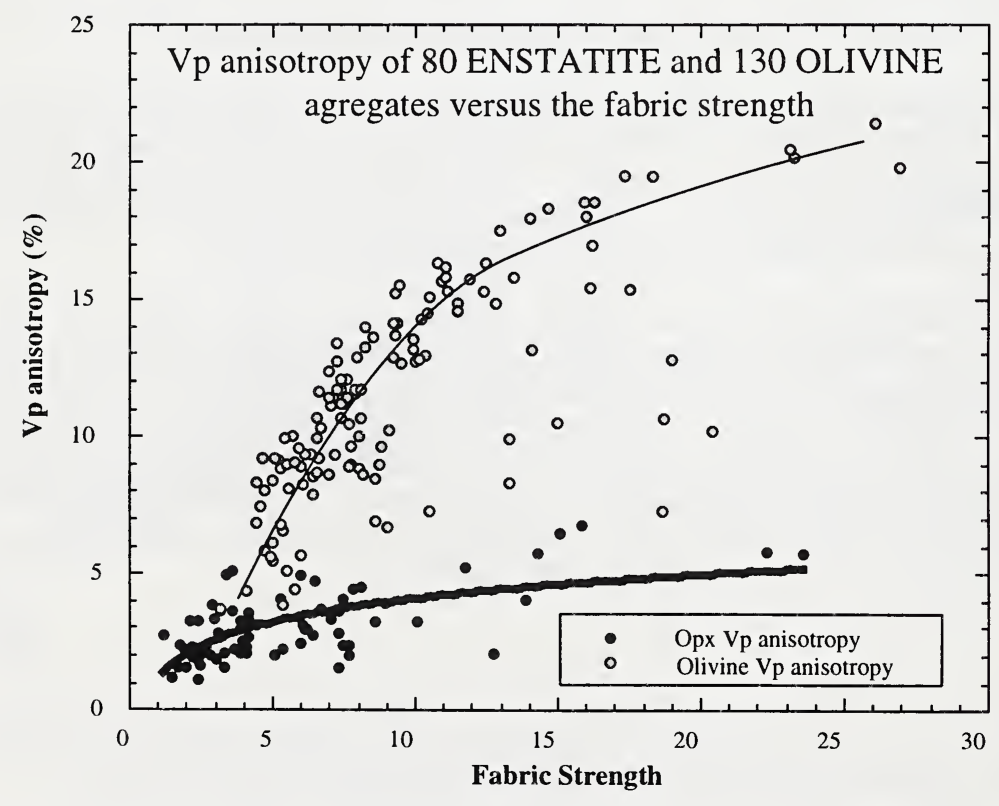


On a statistical point of view, we show that seismic anisotropy increases rapidly at low fabric strength before reaching a near saturation level of between 15-20\% for P-waves (see Figure above) and 10$15 \%$ for $\mathrm{S}$-waves.

By systematically analyzing the peridotite seismic properties, a major conclusion is that despite a large variation in the fabric patterns, in the micro-structures and in the geodynamic settings, the seismic properties of the various kind of fabrics have rather similar anisotropies in both magnitude and symmetry.

From the 110 samples from the database, we calculated the average seismic properties. The first interesting feature is that the "mean" sample does not display isotropic results but has the following features (see figure below); the maximum P-wave velocity is parallel to high concentration of [100] axes, which is sub-parallel to the lineation (the E-W axis in the diagrams). The [100] axes distribution has the largest influence in the seismic anisotropy for both $\mathrm{P}$ and $\mathrm{S}$ waves, and the distribution of [001] has an important effect on the shear waves anisotropy.The maximum shear wave splitting (4.5 $\%$ anisotropy) is parallel to the $\mathrm{Y}$ structural direction (in the foliation plane and normal to the lineation) and the fast $\mathrm{S}$-waves propagating in this direction are polarized parallel to the foliation plane. The $\mathrm{X}$ direction (lineation) is almost isotropic but the $\mathrm{Z}$ structural direction (normal to the foliation) has intermediate anisotropy (around 3\%) and the fast polarized S wave is parallel to the lineation (the flow direction).
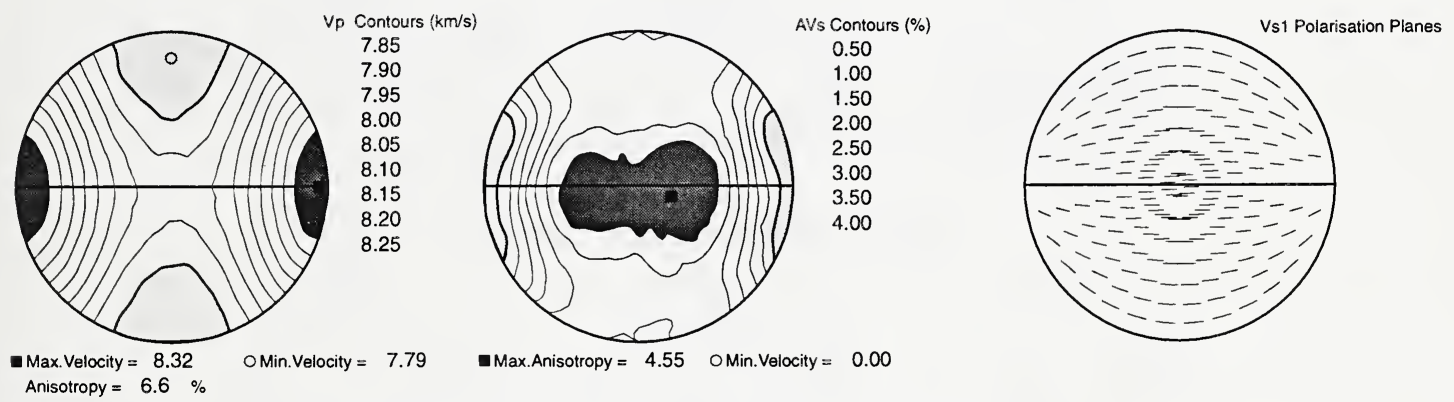

Anisotropy $=6.6 \%$

Average seismic properties of upper mantle rock calculated from 110 peridotites samples (Olivine and orthopyroxene fabrics)

\section{References}

Barruol, G. et Mainprice, D., 3D seismic velocities calculated from LPOs and reflectivity of a lower crustal section Example of the Val Sesia (Ivrea Zone, Northern Italy). Geophys. J. Int., 115: 1169-1188, 1993.

Barruol, G., Helffrich, G. et Vauchez, A., Shear wave splitting around the northern Atlantic: frozen Pangean lithospheric anisotropy? Tectonophysics, 279: 135-148, 1997. 
Ben Ismail W. and D. Mainprice, An olivine fabric database: an interpretative frame for upper mantle seismological studies, Tectonophysics, submitted, 1998.

Mainprice, D. and Nicolas, A., Development of shape and lattice preferred orientations: application to the seismic anisotropy of the lower crust. J. Struct. Geol., 11: 175-189, 1989.

Mainprice D. and Humbert M. , Methods of calculating petrophysical properties from lattice preferred orientation data. Surveys in Geophysics 15, 575-592, 1994.

Mainprice D. and P. G. Silver, Interpretation of SKS-waves using samples from the subcontinental lithosphere, Phys. Earth Planet. Inter., 78: 257-280, 1993.

Silver P. G., Seismic anisotropy beneath the continents: probing the depths of the geology, Annu. Rev. Earth Planet. Sci., 24: 385-432, 1996.

Vauchez A., G. Barruol and A. Tommasi, Why do continents break-up parallel to ancient orogenic belts?, Terra Nova, 9: 62-66, 1997. 